\title{
Editorial
}

\section{Desafíos de la SOCHOG post-pandemia.}

La Sociedad Chilena de Obstetricia y Ginecología, no ha estado ajena a la reinvención que han debido realizar todas las Instituciones, para enfrentar los desafíos impuestos por la pandemia de COVID-19. Todas nuestras actividades presenciales fueron suspendidas, dentro de ellas el XXXVII Congreso en Viña del Mar, previamente cancelado a causa del estallido social.

En este contexto, la SOCHOG se volcó a desarrollar actividades no presenciales que permitieran mantener nuestro contacto con los socios y profesionales afines. De esta manera se buscó satisfacer la creciente demanda académica, no sólo en temas relacionados con SARSCoV-2, sino también en temas de actualización en la especialidad.

Dentro de estas actividades se incluyó la implementación de webinars semanales. Estos webinars abarcaron la mayoría de los temas de nuestra especialidad y de actualización en manejo de COVID-19 teniendo una excelente acogida con más de 19 mil visitas en nuestra plataforma de SOCHOGTV.

Desarrollamos nuestra tradicional Jornada de APS de manera remota, con clases grabadas y una sesión de mesas redondas, que tuvieron más de 600 asistentes. Por primera vez nuestra Sociedad realizó 5 cursos certificados en un formato a distancia con más de 400 asistentes. Dentro de estos cursos, destacaron por su alto nivel de asistencia Endocrinologia-Ginecológica y Ecografía en Ginecología.

Finalmente, realizamos nuestro XXXVII Congreso en un formato virtual, con más de 900 asistentes. Esto fue un logro que no habría sido posible sin el apoyo de nuestros Socios, y por cierto de la Industria.

Definitivamente el Mundo ha cambiado, y nosotros como Sociedad también debemos hacerlo. En las siguientes líneas, les comparto cuáles son a mi juicio, los principales desafíos que tiene la Sociedad en los ámbitos de Educación Continua y de nuestra Revista. En Educación Continua, el desarrollo tecnológico que llegó con la Pandemia nos permite tener a la mano plataformas de comunicación que, de manera sincrónica o asincrónica, establecen una posibilidad de acceder a una audiencia mucho mayor, de lo que sería posible de manera presencial. El primer desafío es entonces incorporar estas herramientas a nuestro quehacer docente.

El segundo desafío es conocer las necesidades de nuestros socios y profesionales afines, saber que conocimientos quieren profundizar y cuales necesitan actualizar para mejorar su práctica clínica. Con este objetivo, durante el 2020 realizamos encuestas de satisfacción y recolectamos opiniones en las múltiples actividades que desarrollamos. A través de esto, logramos recoger las inquietudes académicas, y esperamos éste 2021 dar respuesta a las demandas recogidas.

Siempre el diseño instruccional es un desafío, lograr poner contenidos claros y evaluar que los alumnos los adquieran, con una experiencia educativa óptima, es central en un proyecto de educación continua. La experiencia que logramos durante el 2020, sin duda, nos permitirá lograr un programa educativo que esté acorde a las exigencias de nuestros futuros alumnos. Nuestro cuarto desafío es la participación, no sólo en términos de quienes toman los cursos, sino también de incorporar a nuestros capítulos como un motor de la docencia. Esa es la razón por la que este año 2021 , todos nuestros capítulos tendrán a cargo módulos de webinars en los temas específicos de sus respectivas subespecialidades. También queremos crear una comunidad educativa con nuestros socios $y$ profesionales afines. Una comunidad que se identifique con el desafío de la mejora continua en la salud de la mujer, a través de un desarrollo profesional responsable basado en la mejor evidencia disponible. Estén atentos ya que nuestra Comunidad SOCHOG, dará que hablar durante el 2021.

Finalmente, les quiero compartir nuestro proyecto con la Revista SOCHOG. Como saben nuestra Revista existe desde 1936, y se ha publicado de manera ininterrumpida desde entonces. El crecimiento el último año ha sido explosivo, pasamos de 8535 usuarios en 2019 a 64448 en el 2020, con más de 112 mil visitas a la página de la Revista. Con una gran demanda por publicar artículos de toda Latinoamérica 
y España. Esto genera una gran demanda de trabajo de nuestro equipo editorial, al cual por cierto agradezco su esfuerzo y compromiso.

Nuestro plan es modernizar nuestra plataforma editorial para dar una mejor respuesta y visibilidad a todos los autores que confían en nosotros para publicar sus artículos. Incrementar el número de nuestros revisores para mantener la respuesta en los plazos acordados. Finalmente, lo más importante, planeamos realizar todas las mejoras necesarias, para que, en el plazo de 4 años, podamos tener indexada nuestra revista en WOS. Sin duda, un objetivo mayor, pero que estamos ciertos que viene a coronar el gran esfuerzo que hacemos para tener una publicación de nuestra especialidad de clase mundial.
El Coronavirus nos ha sacado de nuestra zona de confort y nos obligó a repensar todas nuestras actividades. Los invito a aprovechar esta oportunidad para innovar e incorporarse a nuestras actividades de Educación Continua y nuestra Comunidad SOCHOG, que tienen como objetivo mejorar la calidad de la atención de salud que entregamos a nuestras mujeres.

\author{
Dr. José Andrés Poblete \\ Presidente \\ Sociedad Chilena de Obstetricia y Ginecología.
}

